\title{
Dukungan Sosial pada Survivor Kanker di Medan
}

\section{Social Support for Cancer Survivors in Medan}

\author{
Kenrick Chang*, Meilisia Tri Gunawan, Hendra Jaya, Elvy Grashiella, \\ Kenny William \& Winida Marpaung
}

\author{
Fakultas Psikologi, Universitas Prima Indonesia, Indonesia \\ Diterima:30 Agustus 2020; Direview: 31 Agustus 2020; Disetujui:13 September 2020 \\ *Coresponding Email: kenrickchang2@gmail.com, meilisiatrigunawan@gmail.com hiava175@gmail.com, \\ elvygeashiella@gmail.com, kennywilliammm@gmail.com, winida.marpaung@gmail.com
}

\section{Abstrak}

Tujuan dilakukannya penelitian ini adalah untuk melihat gambaran dukungan sosial yang membantu kesembuhan para survivor kanker. Sumber penelitian ini terdiri dari tiga orang subjek penelitian yang adalah seorang survivor kanker dan tiga informan penelitian. Pemilihan sampel menggunakan teknik metode snowball sampling. Data penelitian dikumpulkan dengan menggunakan metode natural observation dan in-depth interview yang kemudian disusun dalam bentuk verbatim. Hasil penelitian menunjukkan bahwa dari bentuk-bentuk dukungan sosial, diantaranya emotional support, tangiable support, informational support, dan companionship support, yang paling menonjol adalah emotional support dan dengan adanya dukungan-dukungan sosial tersebut, penderita kanker lebih merasa percaya diri dan termotivasi untuk sembuh dari kanker.

Kata Kunci: Dukungan Sosial, Survivor Kanker

\begin{abstract}
The purpose of this research is to see how social support helps to cure cancer survivors. The source of this study consists of three research subjects who are a cancer survivor and three research informants. The sample selection used is the snowball sampling method. Research data are collected using natural observation methods and in-depth interview which are then arranged in verbatim form. The results shows that from the forms of social support, including emotional support, tangiable support, informational support, and companionship support, the most prominent is emotional support and with the existence of social supports, cancer sufferers can gain more confident andfeel more motivated to recover from cancer.
\end{abstract}

Keywords: Social Support, Cancer Survivor

How to Cite: Chang, K. Gunawan, M.T. Jaya, H. Grashiella, E. William, K. \& Marpaung, W. (2020). Dukungan Sosial pada Survivor Kanker di Medan. Journal of Education, Humaniora and Social Sciences (JEHSS). 3 (2): 386-393.

\section{PENDAHULUAN}

色 $h t$ ttp://mahesainstitute.web.id/ojs2/index.php/jehss

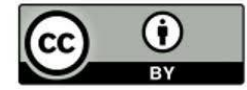

This work is licensed under a Creative Commons Attribution 4.0 
Kesehatan merupakan salah satu kebutuhan manusia dan merupakan kebutuhan paling mendasar berdasarkan hirarki kebutuhan Maslow (Prihantoro, 2015). Agar tetap sehat, manusia mengonsumsi supplemen/vitamin dan makanan bergizi, berolahraga, dan berisitirahat. Tindakan sebaliknya, seperti terlalu banyak mengonsumsi makanan kurang bergizi (seperti fast food) atau minum minuman beralkohol, merokok, kurang beristirahat, dan lingkungan yang kotor, dapat menjadi cikal bakal penyakit bagi manusia.

Penyakit dapat diartikan sebagai gangguan fungsi organisme sebagai akibat dari infeksi atau tekanan dari lingkungan (Irwan, 2015). Salah satu penyakit yang paling ditakuti adalah kanker. Kanker berasal dari bahasa Yunani, karkinos, yang berarti udang karang dan merupakan istilah umum untuk ratusan tumor ganas yang masing-masing sangat berbeda satu sama lain. Berdasarkan data dari American Cancer Society, kanker menjadi penyebab kematian kedua dan diprediksi beberapa tahun kedepan akan melampaui penyakit jantung sebagai penyebab kematian utama saat ini (Kurniasari, Harti, Ariestiningsih, Wardhani, \& Nugroho, 2018)

Dilansir dari CNN Indonesia (13/09/2018 19:42 WIB), Jumlah penderita kanker di seluruh dunia terus meningkat signifikan. Laporan terbaru yang dirilis oleh International Agency for Research on Cancer, Organisasi Kesehatan Dunia (WHO) mengestimasi terdapat 18,1 juta kasus kanker baru dan 9,6 juta kematian yang terjadi pada tahun ini.

Salah satu faktor yang dapat mendukung kesembuhan seorang penderita kanker adalah dukungan sosial yang diterima penderita (Hamdani, et al., 2015; Zuraida, et al., 2015, Hardjo \& Eryanti, 2015). Sarafino dan Timothy (2010) menyatakan bahwa dukungan sosial merujuk pada kenyamanan, kepedulian, penghargaan, atau bantuan yang tersedia untuk seseorang dari orang atau kelompok lain. Orang yang memperoleh dukungan sosial merasa dirinya dicintai, dihargai, dan bagian dari suatu jaringan sosial, seperti keluarga atau komunitas organisasi, yang dapat membantu di saat dibutuhkan (Tarigan, 2018; Siregar, 2018; Nainggolan, et al., 2017).

Dampak dukungan sosial bagi kesembuhan seseorang dari suatu penyakit dapat dijelaskan oleh dua teori yang diusulkan oleh para peneliti, yaitu buffering hypothesis dan direct effects hypothesis (Sarafino\& Timothy, 2010).

Buffering hypothesis menyatakan bahwa dukungan sosial mempengaruhi kesehatan dengan "melindungi" seseorang dari dampak negatif stress yang tinggi melalui dua cara, yaitu: Pertama, ketika seseorang menjumpai stressor yang kuat, seperti krisis keuangan yang parah, mereka yang memiliki dukungan sosial yang tinggi akan menilai situasi tersebut sebagai stress daripada mereka dengan dukungan sosial yang rendah karena orang dengan dukungan sosial yang tinggi akan mengharapkan seseorang yang mereka kenal untuk membantu, seperti dengan meminjamkan uang atau memberi nasihat untuk mendapatkan uang; Kedua, dukungan sosial dapat mengubah respons seseorang terhadap suatu stressor setelah penilaian pertama, contohnya orang dengan dukungan sosial yang tinggi mungkin memiliki seseorang yang memberi solusi atas masalah mereka atau menyemangati mereka untuk "melihat sisi baiknya", sedangkan orang dengan dukungan sosial yang rendah berkemungkinan kecil memiliki kelebihan-kelebihan tersebut sehingga dampak negatif stress lebih besar bagi mereka.

Direct effects hypothesis menegakkan bahwa dukungan sosial bermanfaat bagi kesehatan dan kesejahteraan seseorang terlepas dari jumlah pengalaman stress seseorang. Orang dengan dukungan sosial yang tinggi mungkin memiliki perasaan dimiliki dan dihargai yang tinggi. Dampak positif yang dihasilkan tersebut mungkin bermanfaat bagi kesehatan terkhususnya stress: hasil penelitian dan tes laboratorium telah menemukan tingkat tekanan darah yang rendah pada kalangan dewasa paruh baya dan dewasa muda dengan tingkat dukungan sosial yang tinggi terlepas dari tingkat stress yang

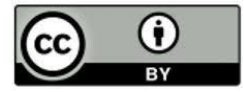

This work is licensed under a Creative Commons Attribution 4.0 


\section{Kenrick Chang, Meilisia Tri Gunawan, \& Hendra Jaya Dukungan Sosial pada Survivor Kanker di Medan}

mereka miliki. Orang dengan dukungan sosial yang tinggi juga lebih memungkinkan untuk menjalani gaya hidup yang sehat karena merasa dipedulikan dan dibutuhkan.

Dukungan sosial berkemungkinan untuk menunjang kesembuhan seseorang dari suatu penyakit, khususnya penyakit kronis seperti kanker. Namun saat ini, dukungan tersebut masih kurang terealisasikan di tengah masyarakat, khususnya bagi para penderita penyakit kronis. Untuk meninjau lebih lanjut, maka peneliti tertarik untuk meneliti "Gambaran Dukungan Sosial pada Survivor Kanker" guna mengetahui gambaran dukungan sosial yang mempengaruhi kesembuhan para survivor kanker.

\section{METODE PENELITIAN}

Metode yang digunakan dalam penelitian ini adalah penelitian kualitatif. Menurut Fitrah dan Luthfiyah (2018) penelitian kualitatif merupakan suatu prosedur penelitian yang menggunakan data deskriptif berupa kata-kata tertulis atau lisan dari orang-orang dan pelaku yang dapat diamati. Penelitian ini mengutamakan kemampuan penelitinya dalam mendeskripsikan pengamatannya secara tertulis dan menginterpretasikan hasil observasi yang telah didapatkan oleh peneliti.

Subjek yang digunakan pada penelitian ini adalah penderita kanker dalam masa remisi/cancer survivor baik laki-laki maupun perempuan dari berbagai rentang usia. Jumlah subjek yang digunakan dalam penelitian ini adalah enam orang yang terdiri dari tiga orang survivor kanker dan masingmasing wali/orangtua subjek. Prosedur pengambilan subjek dilakukan dengan menggunakan teknik snowball sampling. Snowball sampling diartikan sebagai memilih sumber informasi mulai dari sedikit kemudian makin lama makin besar jumlah sumber informasinya, sampai pada akhirnya benar-benar dapat diketahui sesuatu yang ingin diketahui dalam konteksnya (Yusuf, 2016).

Teknik pengambilan data yang digunakan adalah wawancara dan observasi. Pada penelitian ini, wawancara yang digunakan adalah in-depth interview. Menurut Mason pada buku Morris (2015) in-depth interview merupakan percakapan antara dua individu yang mendiskusikan topic dengan minat yang sama dan secara ideal didiskusikan dengan rileks, terbuka, dan jujur. Peneliti juga melaksanakan observasi natural, yaitu pengamatan yang langsung pada situasi riil subjek tanpa usaha untuk memanipulasi serta mengontrol perilaku observe (Ni'matuzahroh \& Prasetyaningrum, 2018). Teknik observasi ini digunakan untuk menghindari faking yang dilakukan oleh subjek penelitian.

Fokus dari penelitian ini adalah bentuk dukungan sosial yang tergambar dalam mendukung kesembuhan survivor kanker. Menurut Uchino (2004, dalam Sarafino \& Smith 2014) terdapat empat bentuk dukungan sosial, diantaranya:

Tabel 1. Bentuk-Bentuk Dukungan Sosial

\begin{tabular}{lll}
\hline No. & Bentuk-Bentuk Dukungan Sosial & Indikator \\
\hline 1 & Emotional support & $\begin{array}{l}\text { Menunjukkan rasa empati, peduli, perhatian, penghargaan } \\
\text { positif, dan dorongan terhadap seseorang }\end{array}$ \\
\hline 2 & Tangiable support & $\begin{array}{l}\text { Memberi bantuan langsung seperti memberi pinjaman uang } \\
\text { atau membantu mengerjakan tugas-tugas tertentu }\end{array}$ \\
\hline 3 & Informational support & $\begin{array}{l}\text { Memberi saran, arahan, nasihat, atau umpan balik terhadap } \\
\text { keadaan seseorang }\end{array}$ \\
\hline 4 & Companionship support & Memberikan ketersediaan untuk menghabiskan waktu dengan \\
& & seseorang \\
& & Memberikan perasaan keanggotaan dalam kelompok \\
\hline
\end{tabular}

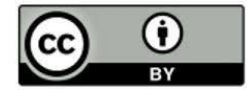

This work is licensed under a Creative Commons Attribution 4.0 


\section{HASIL PENELITIAN DAN PEMBAHASAN}

Penelitian ini menggunakan 3 (tiga) orang subjek sebagai sumber data utama. Ketiga subjek tersebut terpilih dengan menggunakan teknik "snowball sampling". Ketiga subjek yang terpilih memiliki karakteristik yang sama, yaitu merupakan seorang cancer survivor. Teknik ini digunakan demi kelancaran penelitian dan tercapai nya tujuan dari penelitian ini. Penelitian ini menggunakan teknik wawancara in-depth interview dan observasi dalam mengumpulkan data.

\begin{tabular}{|c|c|c|c|c|c|c|c|}
\hline Subjek & $\begin{array}{l}\text { Usia } \\
\text { (Tahun) }\end{array}$ & $\begin{array}{l}\text { Jenis } \\
\text { Kelamin }\end{array}$ & $\begin{array}{l}\text { Suku/ } \\
\text { Agama }\end{array}$ & $\begin{array}{l}\text { Pekerjaan/ } \\
\text { Pendidikan }\end{array}$ & $\begin{array}{l}\text { Riwayat } \\
\text { (Kanker } \\
\text { Stadium) }\end{array}$ & $\begin{array}{l}\text { Usia } \\
\text { terdiagnosa }\end{array}$ & $\begin{array}{l}\text { Lama } \\
\text { remisi/ } \\
\text { Survive }\end{array}$ \\
\hline WS & 23 & Laki-laki & $\begin{array}{l}\text { Tionghoa } \\
\text { (Buddha) }\end{array}$ & Admin Staff & $\begin{array}{l}\text { Leukimia } \\
\text { (Stadium awal) }\end{array}$ & 17 tahun & $\begin{array}{l}7 \text { tahun } \\
\text { (sekarang) }\end{array}$ \\
\hline V & 16 & Perempuan & $\begin{array}{l}\text { Tionghoa } \\
\text { (Kristen) }\end{array}$ & $\begin{array}{l}\text { Pelajar } \\
\text { (SMP) }\end{array}$ & $\begin{array}{l}\text { ALL Leukimia } \\
\text { (Low Risk) }\end{array}$ & 7 tahun & $\begin{array}{l}10 \text { tahun } \\
\text { (sekarang) }\end{array}$ \\
\hline \multirow{2}{*}{ RG } & \multirow{2}{*}{48} & \multirow{2}{*}{ Perempuan } & \multirow{2}{*}{$\begin{array}{l}\text { Batak } \\
\text { (Kristen) }\end{array}$} & \multirow{2}{*}{ Saleswoman } & $\begin{array}{l}\text { Mulut Rahim } \\
\text { (Stadium 2b) }\end{array}$ & 36 tahun & 5 tahun \\
\hline & & & & & Payudara & 41 tahun & $\begin{array}{l}7 \text { tahun } \\
\text { (sekarang) }\end{array}$ \\
\hline
\end{tabular}

Tabel 2. Gambaran Umum Subjek

Dari hasil penelitian, didapatkan bahwa dukungan sosial sangat penting dalam membantu subjek pertama untuk bangkit dari perasaan pasrah terhadap keadaannya saat itu. Diketahui pada akhirnya sumber dukungan subjek berasal dari sahabat, keluarga dan dokter dari subjek. Sahabat subjek memberi dukungan dalam bentuk tangible, informational dan companionship. Mereka adalah satu dari beberapa orang yang mengetahui terlebih dahulu mengenai keadaan subjek saat itu dan dilihat dari usia subjek saat itu yang masih remaja, ada kecenderungan subjek untuk lebih dekat dengan peer group nya. Sahabat-sahabat subjek pun tidak menjauhi subjek, namun sebaliknya semakin dekat dengan subjek, senantiasa mengingatkan subjek untuk tidak mudah lelah, cepat sembuh agar dapat bermain bersama. Keluarga subjek juga memberi dukungan berupa semangat dan juga mengingatkan subjek untuk memilah makanan yang hendak dikonsumsi serta untuk rutin mengonsumsi obat. Dokter juga terlibat dalam memberikan anjuran-anjuran tentang pola makan, pola hidup, dan hal-hal lain demi mempercepat proses kesembuhan subjek. Subjek awalnya sempat merasa pasrah akan keadaannya, namun dikarenakan semua dukungan yang didapatkan tersebut, subjek pun akhirnya survive

Emotional support, Menunjukkan rasa empati, peduli, perhatian, penghargaan positif, dan dorongan terhadap seseorang. Subjek mendapatkan Emotional support dari orang tuanya. Hingga subjek tidak terlalu merasa tertekan apa yang telah ia alami sekarng "Ya orangtua saya menyemangatkan saya agar saya tidak putus asa, membantu saya mengingatkan untuk tetap berfikiran positif selalu." ( I-10139 - I-10142).

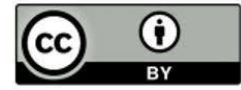

This work is licensed under a Creative Commons Attribution 4.0 
Selain itu subjek juga mendapatkan dukungan dari temannya "Ya pertama-tama dia kan Cuma cerita pada 2 atau 3 temannya saja jadi kami sebagai teman dekatnya ya kami kasih suport kepadanya, kasih doa ya seperti sekedar gitu saja sih..." (I-10081 - I-10084).

Dan.... "Ya, pada saat walikelas kami tau dan walikelas kami memberitahukan pada teman sekelas kami kami mulailah mengumpulkan dana untuknya.." ( I -10086 - I -10088).

Tangible support, Memberi bantuan langsung seperti memberi pinjaman uang atau membantu mengerjakan tugas-tugas tertentu. Subjek mendapatkan Tangible support dari gurunya. Hingga subjek tidak terlalu tertinggal belajarnya dan selalu mendapatkan bimbingan dari gurunya. saat subjek masih sekolah dan dalam perawatan intensif. "Banyak sih, yang saya ingat dulu guru saya itu membantu saya memberikan rangkuman pelajaran yang saya lewatkan..." (I-10112 - I -10114)

Informational support, Memberi saran, arahan, nasihat, atau umpan balik terhadap keadaan seseorang. Subjek juga mendapatkan saran ataupun alternatif yang diberikan dokter pada subjek. Dimana subjek dianjurkan agar lebih menjaga pola hidupnya dan alternatif lain agar tidak membebani biaya pengobatan "Yaa dokter menganjurkan saya untuk menjaga pola hidup saya dan rutin minum obat..." (I-10189 - I -10190).

Dan awalnya dari biaya bayar sendiri menjadi bpjs, "Kalau tentang biaya saya awalnya pakai uang orangtua, lalu saya dianjurkan oleh dokter untuk menggunakan BPJS.." (I-10294 - I -10296).

Companionship support, Memberikan ketersediaan untuk menghabiskan waktu dengan seseorang, memberikan perasaan keanggotaan dalam kelompok Subjek banyak yang mendukungnya baik itu dalam keluarga maupun temannya hingga ia mendapatkan penerimaan dari mereka, "Ya banyak sih, terutama orangtua saya, guru saya, sahabat saya, dan saudara-saudara saya...." (I-10135 - I -10136).

Hal lain yang subjek dapatkan dari perlakuan sahabatnya untuk subjek, "Sahabat saya berkata kalau "saya harus tetap semangat lah nanti siapa lagi yang main COC bareng sama aku" gitu hahahha...." (I-10145 - I -10147)

Subjek kedua menderita kanker pada usia yang masih sangat dini, yaitu berusia 7 tahun. Pada saat itu subjek bahkan merasa bingung kenapa dirinya harus diinfus, disuntik, dan diopname di rumah sakit. Subjek juga bingung mengapa banyak orang datang membawa hadiah untuknya. Subjek hanya mengetahui bahwa orangtuanya terpukul akan keadaannya tersebut. Dukungan utama subjek adalah dari sang ayah. Subjek mengaku bahwa setiap hari nya selalu ditemani papa dan subjek akan selalu merasa aman dengan ada nya sang ayah bersamanya. Di satu waktu ketika rambut subjek hendak dicukur, subjek menolak awalnys, namun sang ayah pun membiarkan diri dicukur botak sehingga dia bersama dengan putrinya, sang subjek, botak. Subjek bersyukur akan kehadiran ayah dan dukungan-dukungan banyak orang yang membantu kesembuhannya. Namun, dukungandukungan tersebut memunculkan kecenderungan subjek untuk mencoba menyenangkan setiap orang yang ada di sekitarnya. Tetapi sang ayah senantiasa mendukung dan menjelaskan pada subjek bahwa yang dapat dilakukan subjek adalah tetap bertahan hidup dan bersyukur akan kehidupannya. Dengan semua dukungan yang telah diterima subjek tersebut, subjek dapat melewati semua pengobatan dengan baik dan telah survive 10 tahun dari kanker.

Emotional support, Menunjukkan rasa empati, peduli, perhatian, penghargaan positif, dan dorongan terhadap seseorang. Subjek kebanyakan mendapatkan emotional support nya dari keluarganya, terkhusus ayah nya, "Papa biasa akan menenangkan saya, memeluk saya, memberitahu saya semuanya akan baik-baik saja, memberikan saya ceramah tentang kehidupan" (II-100277 - II100281)

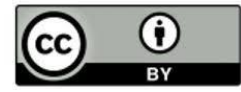

This work is licensed under a Creative Commons Attribution 4.0 
Subjek juga mendapat emotional support dari lingkungannya, "..saya cukup bersyukur karena saya mendapat banyak perhatian, kasih sayang, dan dukungan dari sekitar saya sampai saya tidak bisa membayangkan apa yang terjadi tanpa itu semua." (II-100329 - II-100334)

Tangible support, Memberi bantuan langsung seperti memberi pinjaman uang atau membantu mengerjakan tugas-tugas tertentu. Dukungan dalam bentuk ini datang dalam bentuk hadiah dan dana dari lingkungannya bagi subjek, "Saat itu, saya merasa senang karena mereka datang dan membawa banyak hadiah..." (II-100121 - II-100123)

"... khususnya sekolah saya, mereka memberikan donasi yang jumlahnya saya tidak ingat, pastinya sangat besar jumlahnya sehingga bisa membiayai seluruh pengobatan saya" (II-100211 - II100215)

Informational support, Memberi saran, arahan, nasihat, atau umpan balik terhadap keadaan seseorang. Dukungan ini datang dalam bentuk arahan dari berbagai sumber demi menunjang kesembuhan subjek, "Papa sampai membeli buku-buku yang berkaitan dengan kanker, mencari informasi dari internet dan mungkin juga mendengar saran-saran dari dokter" (II-100301 - II100305)

Companionship support, Memberikan ketersediaan untuk menghabiskan waktu dengan seseorang, memberikan perasaan keanggotaan dalam kelompok. Subjek memperoleh dukungan ini dari lingkungan dan keluarga, terkhusus dari adik subjek sendiri, "Dia sangat baik. Dia selalu menemani saya di rumah sakit sampai dia rela untuk tidak masuk sekolah untuk menemani saya..." (II100234 - II-100237)

Berbeda dari kedua subjek sebelumnya, subjek ketiga menderita kanker pada usia yang sudah tidak muda, yaitu pada usia 36 tahun subjek menderita kanker mulut rahim dan setelah beberapa saat pulih dari kankernya, subjek menderita kanker payudara di usia 41 tahun. Di usianya yang sudah tidak belia, dukungan utamanya adalah dari keluarganya sendiri, yaitu suami dan anakanaknya. Sang suami senantiasa menemani dan melayani subjek selama subjek dirawat di rumah sakit dan anak-anak subjek juga turut memberi semangat dan dukungan doa bagi subjek agar lekas sembuh. Dukungan lain yang mendukung adalah dukungan dari perusahaan tempat subjek bekerja yang senantiasa datang menjenguk dan membantu biaya pengobatan dari subjek sehingga subjek tidak harus membayar terlalu banyak untuk pengobatannya. Dukungan spiritual subjek juga membantu meneguhkan subjek. Kedekatan subjek dengan Tuhan Yang Maha Esa membuat subjek bertumbuh secara rohaniah dan psikologis yang membuat subjek tidak khawatir atau takut lagi karena dengan campur tangan Yang Mahakuasa melalui orang-orang disekitar yang mendukungnya, subjek menjadi semakin yakin akan kesembuhannya. Pada akhirnya, subjek dinyatakan sembuh dan telah survive dari kanker hingga saat ini.

Emotional Support, menunjukkan rasa empati, peduli, perhatian, penghargaan positif, dan dorongan terhadap seseorang. Subjek sempat merasa khawatir dan putus asa. Tetapi karena dukungan keluarga dan rekan kerja nya, subjek jadi dapat melalui dengan baik. "Dan juga anak anak ya, jadi tadi saya sudah sampaikan kalau anak anak lebih kepada doa ya lebih kepada doa termasuk suami jg doa dan kalau perhatian suami itu emm apa ya? Selama menjalani kemo selama menjalani radiasi emm saya belum pernah liat dia bersungut sungut, melayani saya buat jus kadang ya, benar benar dia melayani saya dengan tulus, jadi em karena dia melayani saya dengan tulus tidak ada rasa emmm emm iya saya mungkin timbul rasa percaya diri, jadi ya timbul rasa percaya diri oh ini suami saya masih sayang kok sama saya gitu ya, anak anak butuh support saya ya gitu,..." (III-10074 - III10087)

“...mereka bukan hanya simpati tapi mereka juga empati gitu, empati dalam arti perhatian termasuk tim saya gitu ya, atasan saya, tim saya, sahabat sahabat saya. Benar benar mereka itu tahu

3ब्लिक http://mahesainstitute.web.id/ojs2/index.php/jehss

Nyahesainstitut@gmail.com

391

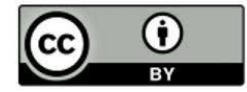

This work is licensed under a Creative Commons Attribution 4.0 
saya dikemo saya tidak berdaya gitu ya, jadi tim saya itu menyampaikan kamu tenang..." (III-10136 III-10142)

Tangible Support, memberi bantuan langsung seperti memberi pinjaman uang atau membantu mengerjakan tugas-tugas tertentu. Subjek mendapatkan bantuan dari asuransi dan perusahaan untuk biaya penyembuhan. "Oh kalau bantuan material itu saya punya asuransi yah, jadi puji tuhan semuanya karena saya dibiayai asuransi ya, saya juga dibayar sama kantor jadi saya tidak ada mengeluarkan uang. Itu semua dari saya punya kantor" ( III-10272 - III-10276)

Informational Support, memberi saran, arahan, nasihat, atau umpan balik terhadap keadaan seseorang. Dokter memberikan beberapa informasi yang menyemangati subjek dan juga memberi arahan untuk check up. "...dia pernah bilang gini "bu rena, kalau kamu bisa melewati 5 tahun maka kamu akan seperti orang yang ga pernah kanker lagi, gitu... dan ini saya melalui 7 tahun..." (III-10240 - III-10243)

"Sebenarnya kalau orang yang sudah pernah kena kanker anjurannya 6 bulan sekali medical check jadi karena ini semuanya sudah bagus jadi dia suruh saya setahun sekali aja gitu..." (III-10257 III-10260)

Companionship support, memberikan ketersediaan untuk menghabiskan waktu dengan seseorang, memberikan perasaan keanggotaan dalam kelompok. Suami subjek memberikan pelayanan yang tulus kepada subjek yang sedang sakit. "...kalau perhatian suami itu emm apa ya? Selama menjalani kemo selama menjalani radiasi emm saya belum pernah liat dia bersungut sungut, melayani saya buat jus kadang ya, benar benar dia melayani saya dengan tulus, jadi em karena dia melayani saya dengan tulus tidak ada rasa emmm emm iya saya mungkin timbul rasa percaya diri, jadi ya timbul rasa percaya diri oh ini suami saya masih sayang kok sama saya gitu ya..." (III-10077 - III10086)

Dari ketiga subjek tersebut dapat terlihat bagaimana dukungan sosial yang tergambar selama subjek menderita kanker sangatlah penting dalam mendukung kesembuhan mereka sehingga mereka dapat survive dari kanker. Hal ini juga terbukti dari penelitian Pratiwi, Mardhiyah, dan Juniarly (2019) yang menyatakan bahwa dukungan sosial turut berperan dalam meningkatkan optimisme pada survivor kanker. Disimpulkan juga dari penelitian ini bahwa dukungan yang paling banyak terlihat dari ketiga subjek adalah emotional support yang kebanyakan berasal dari lingkup sosial yang dekat seperti keluarga, sahabat, dan rekan kerja sedangkan dukungan yang paling sedikit adalah informational support karena dukungan ini sebatas anjuran yang diberikan dokter, seperti anjuran pola makan dan pola hidup yang lebih baik.

\section{SIMPULAN}

Dukungan sosial yang didapat dari setiap subjek sangatlah banyak mulai dari lingkungan sekolah, pekerjaan, kepercayaan terutama keluarga. Di antara semua itu, Emotional Support merupakan dukungan yang paling membantu dan dibutuhkan oleh setiap subjek dalam memperjuangkan kesembuhannya menghadapi kanker. Melalui Emotional Support yang didapat subjek dari keluarga, rekan kerja, sahabat, dan kepercayaannya; berupa pemberian semangat, kasih sayang, dan doa; bentuk dukungan lainnya juga turut datang seperti pemberian saran atau nasihat (Informational Support), pemberian dana/ hadiah (Tangible Support) dan juga rasa kekeluargaan atau persahabatan yang erat (Companionship Support).

\section{DAFTAR PUSTAKA}

Fitrah, M \& Luthfiyah. (2018). Metodologi penelitian: Penelitian kualitatif, tindakan kelas \& studi kasus. Sukabumi: CV Jejak

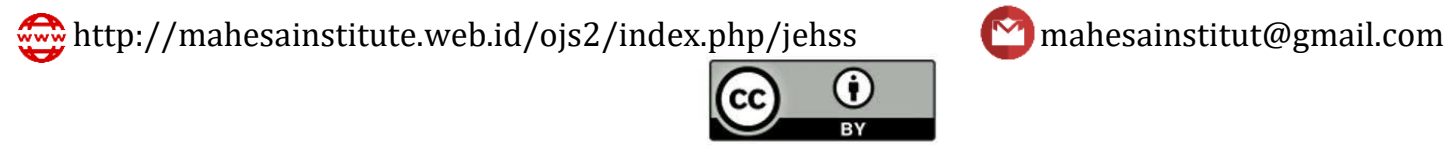


Hamdani, R., Lahmuddin L., Aziz, A., (2015), Hubungan antara Dukungan Sosial dan Kecerdasan Emosional dengan Self-Regulated Learning Siswa. Analitika: 7 (2): 105-117

Hardjo, S., Eryanti N., (2015), Hubungan Dukungan Sosial dengan Psychological Well-Being pada Remaja Korban Sexual Abuse, Analitika: 7 (1): 12-19

Irwan. (2015). Epidemiologi penyakit tidak menular. Yogyakarta: Deepublish

Juniman, P.T. (2018, September 13). WHO: Kanker membunuh hampir 10 juta orang di dunia tahun ini. Diakses dari https://www.cnnindonesia.com/gaya-hidup/20180913133914-255-329910/who-kankermembunuh-hampir-10-juta-orang-di-dunia-tahun-ini

Kurniasari, F. H., Harti, L. B., Ariestiningsih, A. D., Wardhani, S. O., \&Nugroho, S. (2018). Buku ajar: Gizi dan kanker. Malang: UBPress

Morris, A. (2015). A practical introduction to in-depth interviewing. London: SAGE

Nainggolan, W.S.. Chandra, A., \& Sembiring, S.A. (2017). Hubungan Dukungan Sosial dengan Harga Diri pada Mantan Pengguna Narkoba, Jurnal Diversita, 3 (2): 94-100

Ni'matuzahroh \& Prasetyaningrum, S. (2018). Observasi: Teori dan aplikasi dalam psikologi. Malang: UMMPress

Pratiwi, F. J., Mardhiyah, S. A., \& Juniarly, A. (2019). Peran dukungan sosial terhadap optimism pada cancer survivor di rumah sakit Islam Khadijah Palembang. Jurnal Ilmiah Psikologi Terapan, 7(2), 270-278

Prihantoro, A. (2015). Peningkatan kinerja sumber daya manusia melalui motivasi, disiplin, lingkungan kerja, dan komitmen. Yogyakarta: Deepublish

Sarafino, E. P \& Smith, T. W. (2014). Health Psychology: Biopsychosocial interactions (8th edition). New York: John Wiley \& Sons, Inc

Sarafino, E. P., Timothy W. S. (2010). Health psychology: Biopsychosocial interactions seventh edition. Wiley: United States of America

Siregar, N. (2018). Kualitas Hidup Wanita Menopause Ditinjau dari Dukungan Sosial di Kelurahan Sempakata Padang Bulan Medan. JURNAL DIVERSITA, 4(1), 9-15. doi:https://doi.org/10.31289/diversita.v4i1.1566

Tarigan, M. (2018). Hubungan Dukungan Sosial dengan Subjective Well-Being pada Remaja yang Memiliki Orangtua Tunggal. JURNAL DIVERSITA, 4(1), 1-8. doi:https://doi.org/10.31289/diversita.v4i1.1565

Yusuf, A. M. (2016). Metode penelitian kuantitatif, kualitatif \& gabungan. Jakarta: Prenada Media

Zuraida, Kaiman T, Sri S, (2015), Hubungan Kecerdasan Emosional dan Dukungan Sosial Keluarga dengan Burnout, Analitika: 7 (2): 141-149.

3상 http://mahesainstitute.web.id/ojs2/index.php/jehss

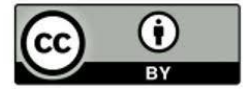

This work is licensed under a Creative Commons Attribution 4.0 